\title{
Incorporating suction in to the interpretation of plate load tests on unsaturated soils
}

\author{
Yi Tang ${ }^{\text {i) }}$, Thanh Vo ${ }^{\text {ii)}}$, Hossein A. Taiebat ${ }^{\text {iii) }}$ and Adrian R. Russell ${ }^{\text {iv }}$
}

\begin{abstract}
i) Postdoctoral Researcher, Geotechnical Engineering Department, Nanjing Hydraulic Research Institute, Nanjing 210029,China. ii) Research Associate, School of Civil and Environmental Engineering, University of New South Wales, Sydney 2052, Australia. iii) Deceased, formerly, School of Civil and Environmental Engineering, University of New South Wales, Sydney 2052, Australia. iv) Associated Professor, School of Civil and Environmental Engineering, University of New South Wales, Sydney 2052, Australia.
\end{abstract}

\begin{abstract}
Results of plate load tests performed on saturated and unsaturated silty sand samples are presented. Very little is known about how to interpret the plate load test when performed on unsaturated soils comprising silt-sand mixtures, as the few published studies have been limited to either unsaturated clean sands or clays. The new plate load test results are interpreted using a bearing capacity equation, applicable when non-uniform $\chi s$ profiles prevail in the soil, where $\chi s$ is the contribution of suction to the effective stress. The interrelation between $\chi s$, strength and bearing capacity is shown. There is a good agreement between measured and computed bearing capacities. Assuming $\chi s$ remains constant during a plate load test, compared to assumptions of constant suction or constant moisture content, simplifies interpretation without significant loss of accuracy. For a particular soil density, the bearing capacity for an unsaturated condition is found to be much larger than that for a fully saturated condition. It is also shown that the effect of suction on the bearing capacity is dependent on the initial location of the hydraulic state on the soil-water characteristic curve. Failing to account for suction and the hydraulic loading history may lead to incorrect interpretations. It is also demonstrated how plate load tests may be used to infer the value of $\chi s$ at the soil surface.
\end{abstract}

Keywords: plate load test, bearing capacity, suction, hydraulic hysteresis

\section{INTRODUCTION}

The plate load test (PLT) is a widely used field test to determine a soil's ultimate bearing capacity and settlement under a given load. Many PLTs are performed on unsaturated soils. There is a need to understand the response of these tests to be able to evaluate or back-calculate the strength parameters of the ground properly so shallow foundations can be designed. Laboratory model footing tests (Oloo 1994; Mohamed and Vanapalli 2006; Oh and Vanapalli 2011) and in-situ PLTs (Consoli et al. 1998; Costa et al. 2003; $\mathrm{Xu}$ 2004) showed that the bearing capacity is significantly increased by suction in an unsaturated soil. The effects of suction may be accounted for using empirical correlations (Costa et al. 2003) or by considering it as an apparent cohesion (Vanapalli and Mohamed 2013; Vahedifard and Robinson 2016).

Hydraulic hysteresis is a phenomenon which gives rise to non-unique relationship between suction and degree of saturation in unsaturated soils. The suction value corresponding to a degree of saturation depends on whether the soil has undergone a drying or wetting process prior to achieving the current state. It has been found that the mechanical behaviour of unsaturated soil is influenced by the hydraulic hysteresis (e.g.
Nishimura and Fredlund 2002; Khalili and Zargarbashi 2010; Pedroso 2015). A recent study (Tang et al. 2017) also found this phenomenon to have significant influences on the bearing capacity. However, no interpretations of model footing test results and PLT results have considered how suction may have differing influences on bearing capacity depending on whether the soil is undergoing wetting or drying.

In this paper results of laboratory-controlled PLTs performed on saturated and unsaturated silty sand are presented. Different suction profiles are developed in unsaturated samples subjected to drying and wetting, by raising and lowering the water table. The suction profiles are determined by the measurements made using vibrating wire piezometers. The PLT results are interpreted using the effective stress concept. The influences of the hydraulic loading histories, soil densities, and suction profiles on the bearing capacities measured in the PLTs are systematically demonstrated.

\section{PLATE LOAD TESTS ON UNSATURATED SILTY SAND}

\subsection{Test soil}

The tested soil is decomposed granite sourced from the catchment area of Lyell dam, NSW, Australia 
(referred to as Lyell silty sand). It is classified to be well-graded silty sand (SM) according to the Unified Soil Classification System (Yang and Russell 2015). The particle size distribution curve with a double logarithmic scale is shown in Fig. 1. It is approximately linear with a slope of 0.39 . Linearity in the double logarithmic plane implies that the soil has a fractal distribution of particle sizes (Russell 2010), the fractal dimension of the particle size distribution is $D_{s}=3-0.39=2.61$. The specific gravity of Lyell silty sand is $G_{s}=2.55$. The maximum dry density $\left(\rho_{\max }\right)$ is 2.02 $\mathrm{g} / \mathrm{cm}^{3}$ corresponding to the minimum void ratio $\left(e_{\min }\right)$ of 0.26 , and the minimum dry density $\left(\rho_{\min }\right)$ is 1.51 $\mathrm{g} / \mathrm{cm}^{3}$ corresponding to the maximum void ratio $\left(e_{\max }\right)$ of 0.69. The critical state friction angle of Lyell silty sand is $\varphi^{\prime}{ }_{c s}=35.7^{\circ}$. The soil is cohesionless at the critical state, i.e., $c^{\prime}=0 \mathrm{kPa}$.

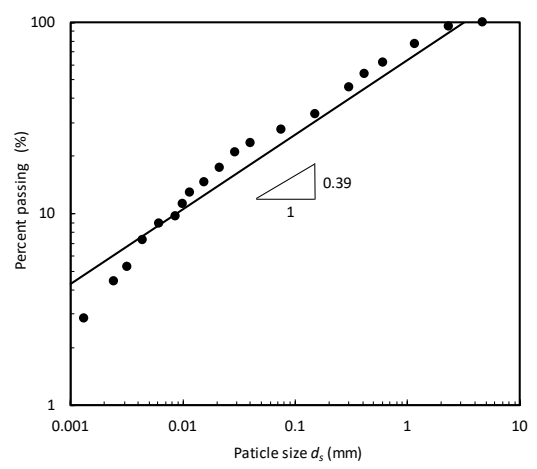

Fig. 1. Particle size distribution for Lyell silty sand in a double logarithmic plane.

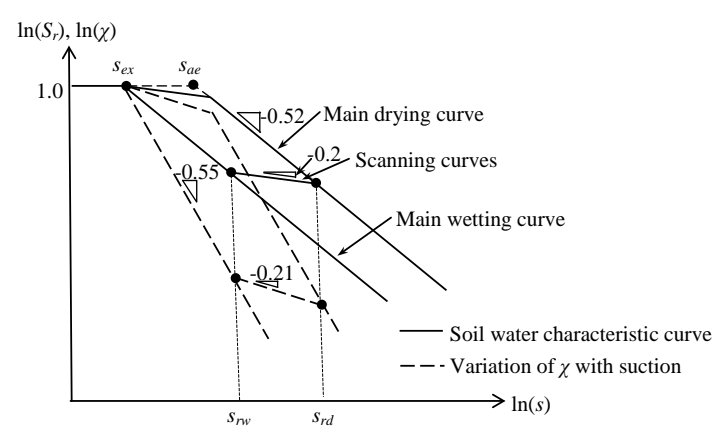

Fig. 2. Soil-water characteristic curve with hydraulic hysteresis and effective stress parameter plotted against suction.

The soil-water characteristic curve (SWCC) of Lyell silty sand is shown in Fig. 2. There is a main drying curve, a main wetting curve and an infinite number of connecting scanning curves in the double logarithmic $s-S_{r}$ plane (Vo et al. 2016). Their mathematical expressions are:

$$
S_{r}=\left\{\begin{array}{lll}
1 & \text { for } & \frac{s}{s_{e}} \leq 1 \\
\left(\frac{s}{s_{e}}\right)^{-0.52} & \text { for } & \frac{s}{s_{e}}>1
\end{array}\right.
$$

$S_{r}=\left\{\begin{array}{l}\left(\frac{s_{r d}}{s_{a e}}\right)^{-0.52}\left(\frac{S}{s_{r d}}\right)^{-0.2} \text { for drying path reversal } \\ \left(\frac{s_{r w}}{s_{e x}}\right)^{-0.52}\left(\frac{S}{s_{r w}}\right)^{-0.2} \text { for wetting path reversal }\end{array}\right.$

where $s$ is the suction, $s_{e}$ is the suction value separating saturated from unsaturated states. $s_{e}=s_{e x}=$ the air expulsion suction which applies when the hydraulic state is on the main wetting curve. $s_{e}=s_{a e}=$ the air entry suction which applies when the hydraulic state is on the main drying curve. $s_{r d}$ and $s_{r w}$ are the points of suction reversal on the main drying and wetting curves, respectively. The slope of the main drying and wetting curves is -0.52 and the slope of scanning curves is -0.2 . Linearity of the main drying and wetting curves in the double logarithmic $s-S_{r}$ plane implies that the pore size distribution is fractal, and the fractal dimension can be inferred to be $D_{p}=-0.52+3=2.48$ (Russell 2014).

Samples with different initial void ratios were tested to take into account the void ratio $(e)$ dependency of the SWCC. The $e$ dependency can be captured in its entirety through $s_{a e}$ and $s_{e x}$ (Russell 2014):

$$
\begin{aligned}
& s_{a e}=1.5 e^{-D_{s}} \mathrm{kPa} \\
& s_{e x}=0.05 e^{-D_{s}} \mathrm{kPa}
\end{aligned}
$$

The effective stress $\left(\sigma^{\prime}\right)$ is (Bishop 1959):

$$
\sigma^{\prime}=\sigma_{\text {net }}+\chi s
$$

where $\sigma_{\text {net }}=\sigma-p_{a}$ is the net stress, $\sigma$ is the total stress and $p_{a}$ is the pore air pressure. $s=p_{a}-p_{w}$ in which $p_{w}$ is the pore water pressure. $\chi$ is the effective stress parameter (Vo et al. 2016):

$$
\begin{aligned}
& \chi=\left\{\begin{array}{lll}
1 & \text { for } & \frac{s}{s_{e}} \leq 1 \\
\left(\frac{s}{s_{e}}\right)^{-0.55} & \text { for } & \frac{s}{s_{e}}>1
\end{array}\right. \\
& \chi=\left\{\begin{array}{l}
\left(\frac{s_{r d}}{s_{a e}}\right)^{-0.55}\left(\frac{S}{s_{r d}}\right)^{-0.21} \text { for drying path reversal } \\
\left(\frac{s_{r w}}{s_{e x}}\right)^{-0.55}\left(\frac{s}{s_{r w}}\right)^{-0.21} \text { for wetting path reversal }
\end{array}\right.
\end{aligned}
$$


The relationship between $\chi$ and $s$ in a double log plane is shown in Figure 2. The dependency of $\chi$ on $e$ is captured through $s_{a e}$ and $s_{e x}$ in Equations (3) and (4).

\subsection{Testing apparatus}

The testing apparatus consists mainly of a steel-framed testing rig, loading devices and a data acquisition system. The rig is $0.69 \mathrm{~m}$ wide by $2.07 \mathrm{~m}$ long by $1.14 \mathrm{~m}$ deep. The water table can be controlled in a sample in the rig by adding and draining water through a valve connected to the bottom of the rig. The front face of the testing rig is plastic plate. The details of the testing rig are shown in Fig. 3.

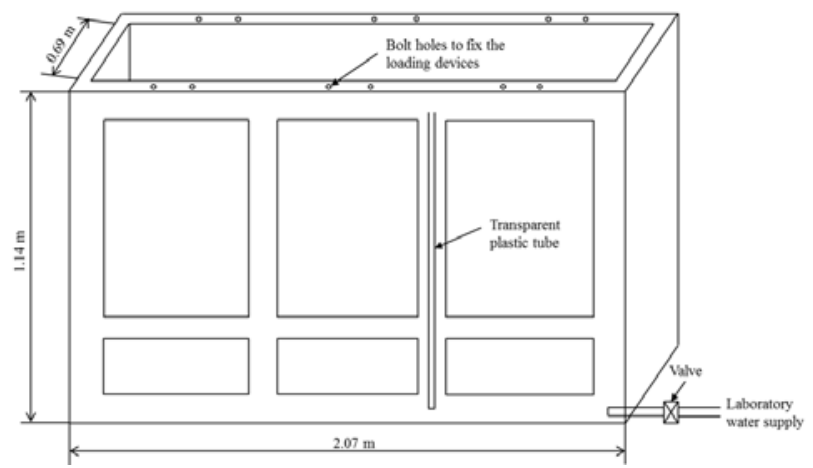

Fig. 3. The details of the testing rig.

The PLT equipment comprises a rigid circular steel plate, a load cell, a vertical displacement transducer and a worm gear actuator. The circular steel plate has a diameter $d$ of $0.15 \mathrm{~m}$. The vertical displacement is applied by a worm gear actuator. A vertical displacement transducer is used to convert the applied displacement into electrical signals. A load cell with a capacity of $45 \mathrm{kN}$ is mounted to measure the load. The details of the loading devices are shown in Fig. 4.

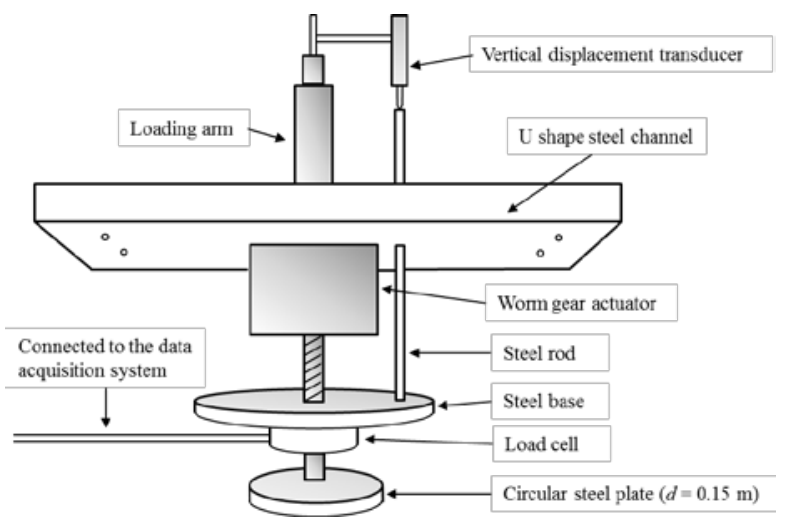

Fig. 4. The details of the loading devices.

Three plate load tests can be conducted at different locations on the surface of one soil sample to check the repeatability of the tests results. The width of the testing rig and the distance between the centres of adjacent plate load tests is $0.69 \mathrm{~m}$. It is 4.6 times of the diameter of the plate $(d=0.15 \mathrm{~m})$ which is sufficient for boundary effects to be negligible and one test not to interfere with the other.

\subsection{Sample preparation and suction measurement}

Before preparing a sample a layer of gravel with a thickness of $200 \mathrm{~mm}$ is placed at the base of the testing rig. Geotextile is then placed on top of the gravel layer to keep the silty sand separate from the gravel and to prevent the small silt and sand particles dropping into the voids of gravel. Silty sand samples are prepared using a combination of pluviation and vibration. The method involves making a soil sample in three layers. Each layer has a thickness of $160 \mathrm{~mm}$ and is placed using dry pluviation with a drop height of $500 \mathrm{~mm}$. A uniform surcharge of $154 \mathrm{kPa}$ is placed on the surface of the three layered sample and the entire testing rig is then vibrated using a mechanical vibrator with a frequency of $80 \mathrm{~Hz}$. In forming a number of samples it is found that the thickness of each layer remains very similar after vibration indicating a uniform density.

Different densities may be achieved by varying the duration of vibration. Soil samples are prepared by vibrating for 3 mins, 6 mins and 9 mins, respectively, corresponding to void ratios of $0.39,0.34$ and 0.29 and relative densities of $0.69,0.82$ and 0.92 .

After preparing the dry samples water is added through the valve connected to the testing rig near the bottom of a soil sample.

Some saturated samples are made unsaturated by subjecting them to a wetting process. This involves holding the water table constant at the same level as the geotextile separating the gravel layer from the silty sand sample. Capillary action then causes the water to move upwards into the voids of the silty sand sample.

A sample is made saturated by allowing the water level to rise to $20 \mathrm{~mm}$ above the sample surface and then allowing the sample to soak for 14 days. In trial tests the degree of saturation at different depths is measured and found to be larger than 0.96 .

A sample is made unsaturated by subjecting it to a drying. This involves lowering the water table to the soil gravel interface. An unsaturated sample is assumed to have reached equilibrium when the changes of suction (measured in the samples) during a 24 hour period are less than $0.1 \mathrm{kPa}$.

Four vibrating wire piezometers are placed at three different depths to measure suction in the soil samples. Holes at different locations of the soil sample are created to insert the piezometers. The soil excavated from each hole is weighed and reduced by an amount that would occupy the volume of the piezometer. The soil is then placed back and compacted to the original density above the piezometer.

Two piezometers are inserted at a depth of $70 \mathrm{~mm}$ (about half of the diameter of the plate) to check the uniformity of the suction at a shallow depth. They also enable suction measurement of the soil close to the soil surface which has the greatest influence on the bearing capacity. Two other piezometers are placed at the 
depths of $220 \mathrm{~mm}$ and $370 \mathrm{~mm}$ (1.5 times and 2.5 times the plate diameter) enabling the suction profile to be established.

\subsection{Test procedure}

A PLT involves positioning the plate on the soil surface and then loading it by imposing a displacement rate of $0.03 \mathrm{~mm} / \mathrm{s}$. A test is terminated when the failure load has been reached and the displacement is continued for a further $5-10 \mathrm{~mm}$. The duration of the test is about 20 mins.

Three PLTs were performed at different locations on the surface of a sample: one test when the sample was saturated and two tests when the sample was unsaturated.

Subsamples may be taken from unsaturated samples immediately after a PLT is conducted. In this study they are taken using a cutting ring sampler (with an inner diameter of $63.2 \mathrm{~mm}$ and a height of $27 \mathrm{~mm}$ ) at locations that are $60 \mathrm{~mm}$ from the piezometers and 100 $\mathrm{mm}$ from the test locations. The degrees of saturation are calculated and used to locate the hydraulic states on the SWCC.

\section{INTERPRETATION OF THE RESULTS OF THE PLATE LOAD TESTS}

\subsection{Plate load test results}

Each PLT has been assigned an identification number according to the relative densities of the soil samples. Figs. 5 to 10 show the load displacement curves obtained for the PLTs performed on saturated and unsaturated samples with different void ratios. The measured bearing capacities listed in Table 1 are defined as the peak load (shown on the figures) divided by the plate area.

Table 1. Measured and calculated bearing capacities for plated load tests.

\begin{tabular}{cccc}
\hline $\begin{array}{c}\text { Test } \\
\text { number }\end{array}$ & Type & $\begin{array}{c}\text { Measured } \\
\text { bearing } \\
\text { capacity }(\mathrm{kPa})\end{array}$ & $\begin{array}{c}\text { Calculated } \\
\text { bearing } \\
\text { capacity }(\mathrm{kPa})\end{array}$ \\
\hline SAT069 & Saturated & 70 & 64 \\
\hline USW069-1 & $\begin{array}{c}\text { Unsaturated } \\
\text { wetting }\end{array}$ & 500 & 361 \\
\hline USW069-2 & $\begin{array}{c}\text { Unsaturated } \\
\text { wetting }\end{array}$ & 463 & 361 \\
\hline SAT082 & Saturated & 101 & 84 \\
\hline USW082-1 & $\begin{array}{c}\text { Unsaturated } \\
\text { wetting }\end{array}$ & 544 & 447 \\
\hline USW082-2 & $\begin{array}{c}\text { Unsaturated } \\
\text { wetting }\end{array}$ & 562 & 447 \\
\hline SAT092 & Saturated & 132 & 108 \\
\hline USD092-1 & $\begin{array}{c}\text { Unsaturated } \\
\text { drying }\end{array}$ & 2546 & 2582 \\
\hline USD092-2 & $\begin{array}{c}\text { Unsaturated } \\
\text { drying }\end{array}$ & 2694 & 2582 \\
\hline
\end{tabular}

In general it is indicated by the load displacement curves that the load increases with the applied displacement to the peak value $P_{\max }$ and then drops or fluctuates slightly with further displacement. The two tests conducted under the same unsaturated condition at different locations on a sample produced (almost) identical load displacement curves and $P_{\max }$ values. For a soil sample with a certain relative density, $P_{\max }$ was larger for an unsaturated sample than a saturated sample. $P_{\max }$ increased with sample density in the tests on both saturated and unsaturated samples, although the samples had different suctions and this too has an influence on $P_{\max }$.

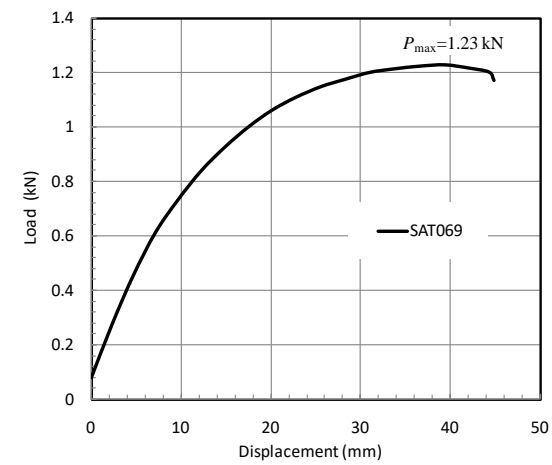

Fig. 5. PLT results for saturated sample with void ratio of 0.39 .

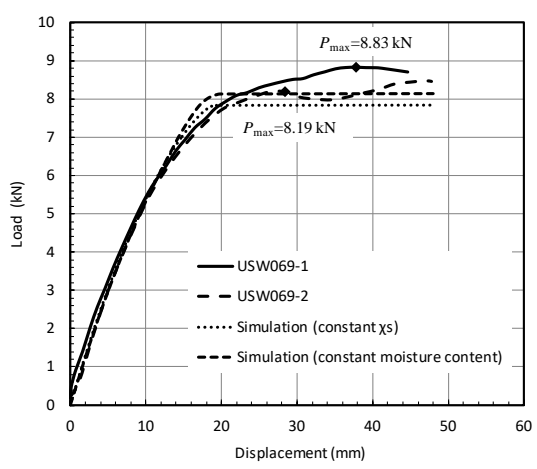

Fig. 6. PLT results and numerical simulation for unsaturated sample having undergone wetting with void ratio of 0.39 .

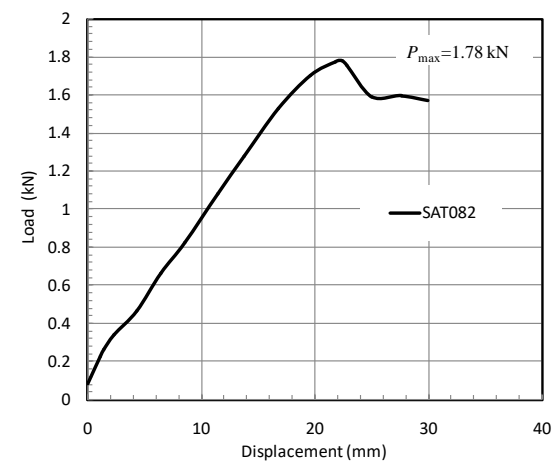

Fig. 7. PLT results for saturated sample with void ratio of 0.34 . 


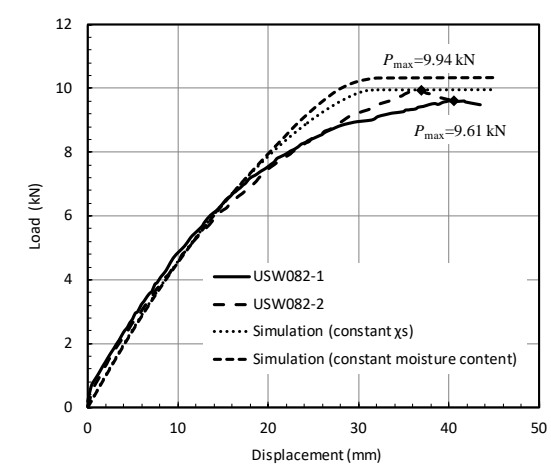

Fig. 8. PLT results and numerical simulation for unsaturated sample having undergone wetting with void ratio of 0.34 .

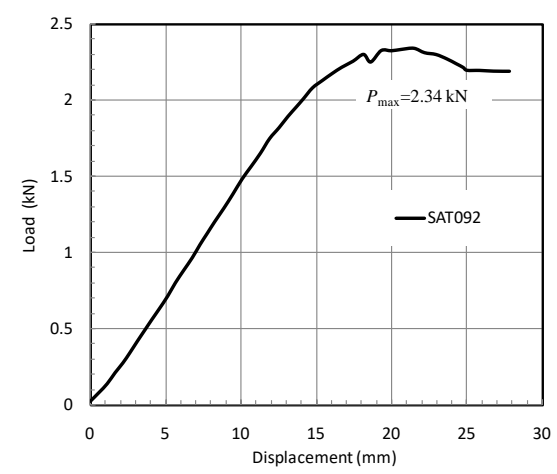

Fig. 9. PLT results for saturated sample with void ratio of 0.29 .

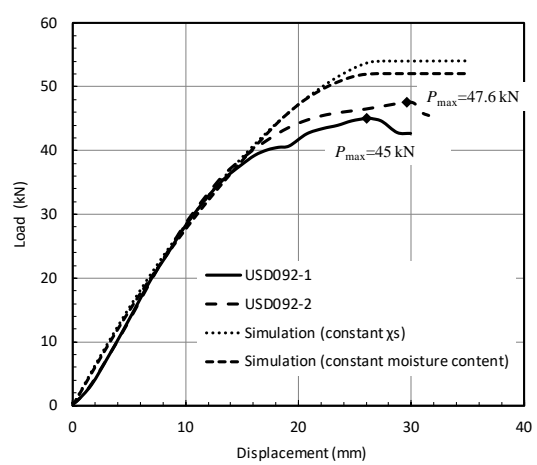

Fig. 10. PLT results and numerical simulation for unsaturated sample having undergone drying with void ratio of 0.29 .

\subsection{Initial locations of hydraulic states on the SWCC}

For the unsaturated tests the suction and degree of saturation values at three depths $(70 \mathrm{~mm}, 220 \mathrm{~mm}$ and $370 \mathrm{~mm}$ ) measured by the piezometers are listed in Table 2. The measured $S_{r}$ and $s$ are plotted on the SWCC in Fig. 11, where the suction has been normalised by $s_{a e}$ to capture the effects of the different void ratios of the samples.

An unsaturated sample which undergoes wetting prior to testing experiences an increase in its $S_{r}$. The corresponding movement of the hydraulic state is along the main wetting curve of the SWCC. An unsaturated sample which undergoes drying immediately prior to testing, starting from a saturated condition, has a hydraulic state which moves along the top scanning curve of the SWCC. It is shown in Fig. 11 that the suction increase which occurred was not large enough for the hydraulic state to move from the top scanning curve on to the main drying curve.

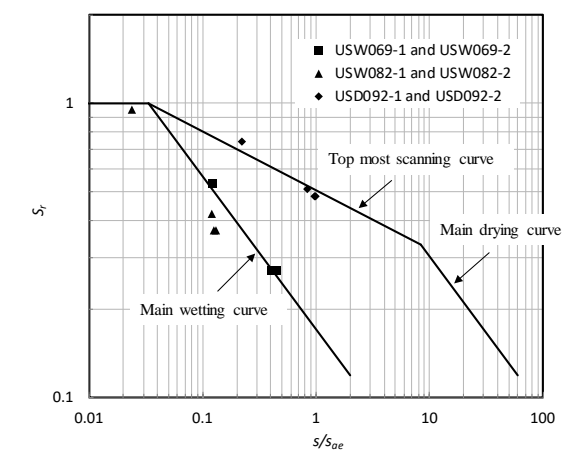

Fig. 11. Plots of measured suction and degree of saturation on a normalized SWCC.

Table 2. suction and degree of saturation at different depths of the unsaturated soil samples and the calculated $\chi$ s.

\begin{tabular}{ccccc}
\hline $\begin{array}{c}\text { Test } \\
\text { number }\end{array}$ & $\begin{array}{c}\text { Depth } \\
(\mathrm{m})\end{array}$ & $\begin{array}{c}\text { Degree of } \\
\text { saturation }\end{array}$ & $\begin{array}{c}\text { Measured } \\
\text { suction } \\
(\mathrm{kPa})\end{array}$ & $\begin{array}{c}\text { Calculated } \\
\chi \mathrm{s}(\mathrm{kPa})\end{array}$ \\
\hline USW069-1 & 0.07 & 0.27 & $7.9,7.8$ & 1.87 \\
and & 0.15 & 0.26 & - & - \\
USW069-2 & 0.30 & 0.27 & 7.2 & 1.81 \\
& 0.37 & 0.53 & - & - \\
\hline USW082-1 & 0.07 & 0.48 & $5,4.8$ & 1.08 \\
and & 0.22 & 0.52 & - & - \\
USW082-2 & 0.30 & 0.51 & 4.6 & 1.84 \\
& 0.37 & 0.74 & - & - \\
\hline USD092-1 & 0.15 & 0.37 & $23.4,22.9$ & 12.4 \\
and & 0.15 & 0.41 & - & - \\
USD092-2 & 0.30 & 0.42 & 21.1 & 11.6 \\
& 0.37 & 0.46 & - & - \\
\hline
\end{tabular}

\subsection{Effect of suction on the bearing capacity}

As shown in Table 1, the test results indicate that suction has a pronounced effect on the bearing capacity. Compared with the fully saturated conditions, the bearing capacity is increased by about 6 times, 4.5 times and 19 times due to suction for the soil samples with void ratios of $0.39,0.34$ and 0.29 , respectively.

The influence of suction on the effective stress and thus the bearing capacity is taken into account through $\chi$ s. It is important to know the way $\chi s$ varies with depth (the $\chi s$ profile). The values of $\chi s$ at different depths are listed in Table 2 (the influence of hydraulic state locations is considered). In all unsaturated samples it was found that $\chi$ s decreases slightly with depth within the shallowest parts of the samples. The reduction of $\chi s$ with depth is more significant in the deepest parts of the 
samples. Bilinear $\chi s$ profiles are assumed here that best fit these experimental measurements. $z$ is used to denote depth (in meters) in a sample. These bilinear $\chi s$ profiles are plotted in Figs. 12 to 14 together with the $\chi s$ values calculated based on the measured $s$.

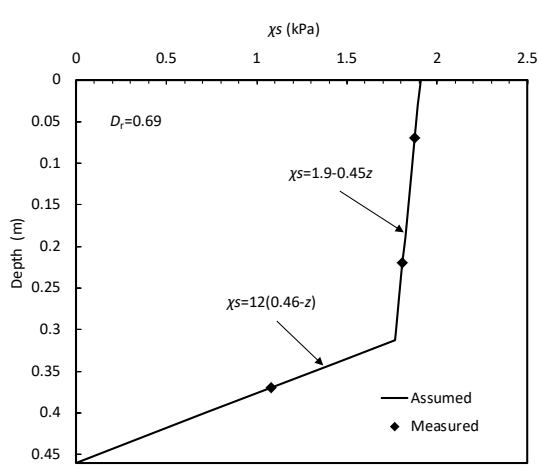

Fig. 12. Assumed $\chi$ s profile for unsaturated sample having undergone wetting with void ratio of 0.39 .

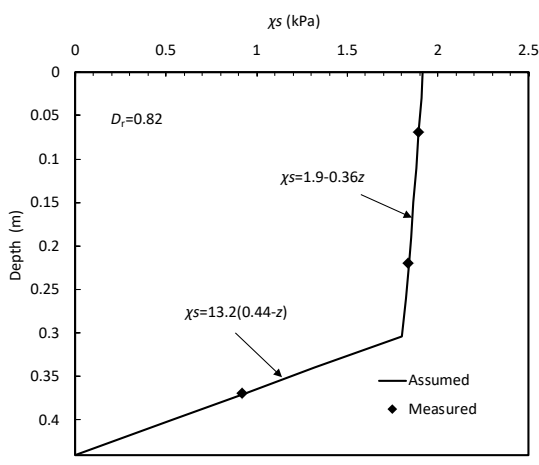

Fig. 13. Assumed $\chi$ s profile for unsaturated sample having undergone wetting with void ratio of 0.34 .

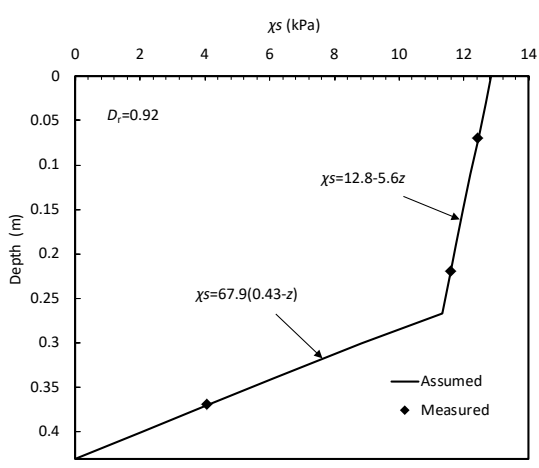

Fig. 14. Assumed $\chi$ s profile for unsaturated sample having undergone drying with void ratio of 0.29 .

\subsection{Numerical modelling of the PLTs}

A series of finite element analyses are performed using the fully coupled flow deformation model for the bearing capacity problem presented by Tang et al. (2017). The soil was assumed to be elastic perfectly plastic and obey the Mohr-Coulomb failure criterion.
The plate is assumed to be rigid and rough. Hydraulic hysteresis and the influence of volume change and $e$ on the SWCC and $\chi$ s were considered.

The input parameters used to generate the numerical results are listed in Table 3 . The elastic moduli, $E$, are calculated based on the load-displacement curves obtained by the plate load tests. Here the peak friction angle $\left(\varphi_{p}^{\prime}\right)$ is assumed to be equal to $38^{\circ}, 39^{\circ}$ and $40^{\circ}$ for soil samples with initial $D_{r}$ of $0.69,0.82$ and 0.92 , respectively, each above the critical state value of $35.7^{\circ}$ and increasing with soil density (Bolton 1986; Maeda and Miura 1999; Salgado et al. 2000).

Table 3. Model parameters used in the interpretations and numerical simulations of the plate load tests.

\begin{tabular}{ccccc}
\hline Test number & $E(\mathrm{kPa})$ & $\varphi_{p}^{\prime}\left(^{\circ}\right)$ & $S_{a e}(\mathrm{kPa})$ & $s_{e x}(\mathrm{kPa})$ \\
\hline SAT069 & 500 & 38 & - & - \\
\hline $\begin{array}{c}\text { USW069-1 and } \\
\text { USW069-2 }\end{array}$ & 3400 & 38 & 17.5 & 0.58 \\
\hline $\begin{array}{c}\text { SAT082 } \\
\text { USW082-1 and } \\
\text { USW082-2 }\end{array}$ & 2900 & 39 & - & - \\
\hline SAT092 & 900 & 40 & - & - \\
\hline $\begin{array}{c}\text { USD092-1 and } \\
\text { USD092-2 }\end{array}$ & 17000 & 40 & 37.3 & 1.24 \\
\hline
\end{tabular}

The duration of the PLT is sufficiently short for the moisture to stay constant in the samples during testing due to the silty sand having a relatively low permeability (Yang et al. 2014). To investigate how sensitive the bearing capacity is to the drainage conditions, a constant moisture content $(\omega)$ and constant $\chi s$ condition were assumed in generating the numerical results. Three sets of numerical results (for rigid and rough circular plates) are compared to experimental data in Figs. 6, 8 and 10. It is shown that considering a wide range of initial densities and hydraulic state locations, numerical result agree well with experimental data and the errors associated with the constant $\chi$ s assumption are less than 5\% for Lyell silty sand. A constant $\chi$ s condition can be assumed in calculation of bearing capacity without loss of significant accuracy.

The numerical analysis was also used to confirm that the $0.69 \mathrm{~m}$ wide sample and $0.69 \mathrm{~m}$ test location spacing was sufficient for boundary effects and interferences to be negligible (less than 1\%).

\subsection{Interpretation using bearing capacity theory}

It is assumed that $\chi s$ has a profile that varies linearly with depth according to:

$$
\chi s=(\chi s)_{0}+K_{\chi s} Z
$$

where $(\chi s)_{0}$ is the value of $\chi s$ at the ground surface and $K_{\chi s}=\partial(\chi s) / \partial z$ is a constant. Vo and Russell (2016) analysed the bearing capacity problem using slip line theory and recognised that $c^{\prime} \cot \varphi \varphi^{\prime}$ and $\chi s$ have similar (and independent) effects on the governing equations. 
The bearing capacity $\left(q_{u}\right)$ of unsaturated soils may be expressed in dimensionless form as:

$$
V=\frac{q_{u}}{c_{0}^{\prime}+(\chi s)_{0} \tan \varphi^{\prime}+q_{s} \tan \varphi^{\prime}}
$$

and is dependent on the dimensionless factor:

$$
F=\frac{\left(K_{c}+K_{\chi s} \tan \varphi^{\prime}\right) B+\gamma_{t} B \tan \varphi^{\prime}}{c_{0}^{\prime}+(\chi s)_{0} \tan \varphi^{\prime}+q_{s} \tan \varphi^{\prime}}
$$

along with the friction angle $\varphi^{\prime} . c_{0}^{\prime}$ is the cohesion at the soil surface, $K_{c}$ is a constant defining the variation of cohesion with depth. $\gamma_{t}$ is the total unit weight of the soil. $B$ denotes the footing diameter and $q_{s}$ is the surcharge applied to the surface of the soil adjacent to the footing.

The slip line theory is used to compute the unique relationships between $V$ and $F$ for different $\varphi^{\prime}$ values for rough circular surface footings. The relationships are presented in charts in Fig. 15. These relationships can be used to determine $q_{u}$ for any combination of $c_{0}^{\prime}, \varphi^{\prime}$, $K_{c}, B,(\chi s)_{0}, K_{\chi s}, q_{s}$ and $\gamma_{t}$.

Note that for a soil that is saturated all the way to the soil surface, and when drained conditions prevail, $(\chi s)_{0}$ may be interchanged with $\left(-u_{w}\right)_{0}$, that is the negative of the pore water pressure at the ground surface, and $K_{\chi s}$ may be interchanged with $K_{u w}$ $=\partial\left(-u_{w}\right) / \partial z$. For hydrostatic conditions $K_{u w}=-\gamma_{w}$.

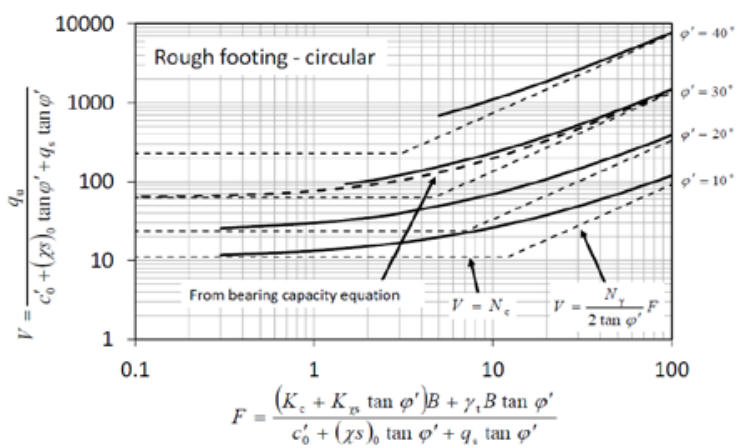

Fig. 15. The unique relationships between $N_{c}$ and $N_{\gamma}$ for different $\varphi^{\prime}$ values, for rough circular footings.

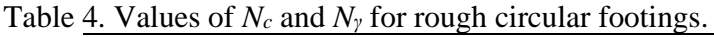

\begin{tabular}{ccc}
\hline$\varphi^{\prime}\left({ }^{\circ}\right)$ & $N_{c}$ & $N_{\gamma}$ \\
\hline 5 & 8.058 & 0.08063 \\
10 & 11.09 & 0.3224 \\
15 & 15.85 & 0.9323 \\
20 & 23.68 & 2.416 \\
25 & $37.32^{*}$ & 6.073 \\
30 & $62.72^{*}$ & 15.52 \\
35 & $114.0^{*}$ & 41.88 \\
40 & $228.5^{*}$ & 123.7 \\
45 & $519.6^{*}$ & 417.7 \\
50 & $1397.0^{*}$ & 1710.0
\end{tabular}

In Fig. 15, as $F \rightarrow 0, V \rightarrow N_{c}$. Also, as $F \rightarrow+\infty, V \rightarrow$ $N_{\gamma} F /\left(2 \tan \varphi^{\prime}\right)\left(N_{c}\right.$ and $N_{\gamma}$ are bearing capacity factors).
These limiting conditions are represented by the straight dash lines. Values of $N_{c}$ and $N_{\gamma}$ (Martin 2004) are given in Table 4 for rough circular footings.

When these values are incorporated in to a bearing capacity equation of the form:

$$
\begin{aligned}
q_{u}= & \left(c_{0}^{\prime}+(\chi s)_{0} \tan \varphi^{\prime}+q_{s} \tan \varphi^{\prime}\right) N_{c} \\
& +\frac{1}{2}\left(K_{c} \cot \varphi^{\prime}+K_{\chi s}+\gamma_{t}\right) B N_{\gamma}
\end{aligned}
$$

the $q_{u}$ values obtained lie below those that would be obtained using the more exact slip line theory, as demonstrated in Fig. 15 for $\varphi^{\prime}=30^{\circ}$. The difference is due to the superposition used in the bearing capacity equation making it approximate and conservative when estimating $q_{u}$ (e.g. Griffiths 1982; Martin 2004).

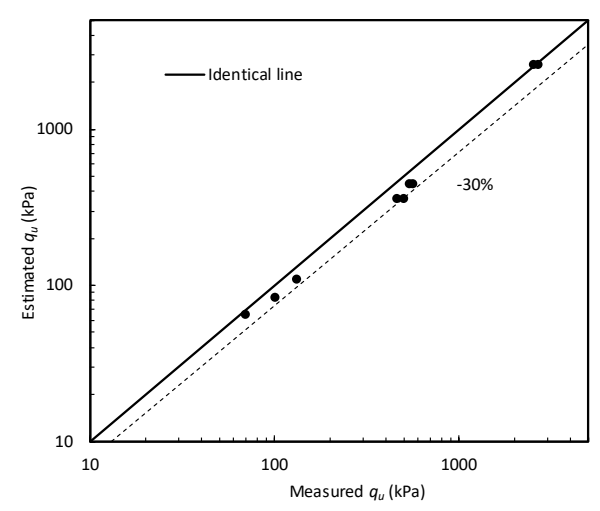

Fig. 16. Comparison between the measured bearing capacities and values calculated using Equation (12).

Lyell silty sand is cohesionless, no surcharge was applied in the experiments, and the surcharge induced by the plate's penetration depth is negligible, so Equation (11) can be simplified to:

$$
q_{u}=\left((\chi s)_{0} \tan \varphi^{\prime}\right) N_{c}+\frac{1}{2}\left(K_{\chi s}+\gamma_{t}\right) B N_{\gamma}
$$

The bearing capacity factors $N_{c}$ and $N_{\gamma}$ are dependent on $\varphi^{\prime}$. The peak friction angles in Table 3 are used in the calculation. The profiles of $\chi s$ in the experiments conducted here are bilinear. Only the $\chi s$ profiles at shallow depths need to be considered since Poulos and Davis (1974) found that the stress in the soil, due to the load applied to a shallow footing, is concentrated within a depth of $1.5 B$ from the footing. The $q_{u}$ values are calculated using Equation (12) assuming a rough plate and are listed in Table 1.

For a given initial $D_{r}$ the $q_{u}$ for an unsaturated condition is clearly larger than that for a saturated condition. This is due to the influences of both $(\chi s)_{0}$ and $K_{\chi s}$ in the calculation (notice that $K_{u w}=-\gamma_{w}=-9.8 \mathrm{kN} / \mathrm{m}^{3}$ for the saturated condition thus the unit weight component of the bearing capacity calculation is significantly reduced). 
Fig. 16 compares the computed $q_{u}$ with the measured values for both saturated and unsaturated conditions. It is shown that, generally, the computed $q_{u}$ lie below the measured $q_{u}$ and the errors associated with Equation (12) are less than 30\%. The differences may be partly due to the assumptions used to compute $N_{c}$ and $N_{\gamma}$ (Martin 2004) and the superposition used in the bearing capacity equation.

\section{CONCLUSIONS}

The results of PLTs performed on the surface of saturated and unsaturated silty sand samples subjected to different densities and suctions are presented in this paper. Different suction profiles were developed in unsaturated samples which underwent drying and wetting processes. The initial locations of hydraulic states on the SWCC were determined through measurements of suction and degree of saturation.

The $\chi s$ profiles were found to be bilinear. The parameters defining the upper part of the bilinear $\chi s$ profile was fed in to a bearing capacity equation to obtain an approximate value of the bearing capacity, as long as the upper part of the bilinear profile represents the $\chi$ s values within the zone of soil that most heavily influence a PLT. Fully coupled finite element analyses show that the values of $\chi s$ may be assumed constant and equal to the initial values during plate loading and the associated errors is less than $5 \%$.

It is observed that the bearing capacity calculated using the bearing capacity equation is slightly lower than those obtained from more exact analyses using slip line theory or finite element analysis. The difference arises from the superposition principal used to establish the bearing capacity equation and the assumption that the $\chi s$ values remain constant during loading. The bearing capacities calculated by the equation are in reasonable agreement to the values measured in the PLTs, with differences less than $30 \%$.

\section{ACKNOWLEDGEMENTS}

Thanks goes to the China Postdoctoral Science Foundation (grant 2018M630575) and the Australian Research Council (grant DP140103142).

\section{REFERENCES}

1) Bishop, A. W. (1959): The principle of effective stress, Teknisk Ukeblad, 106 (39), 859-863.

2) Bolton, M. D. (1986): The strength and dilatancy of sands, Géotechnique, 36(1), 65-78.

3) Consoli, N. C., Schnaid, F. and Milititsky, J. (1998): Interpretation of plate load tests on residual soil site, Journal of Geotechnical and Geoenvironmental Engineering, 124(9), 857-867.

4) Costa, Y. D., Cintra J. C. and Zornberg, J. G. (2003): Influence of matric suction on the results of plate load tests performed on a lateritic soil deposit, Geotechnical Testing Journal, 26(2), 219-226.

5) Griffiths, D. V. (1982): Computation of bearing capacity factors using finite elements, Géotechnique, 32, 195-202.

6) Khalili, N. and Zargarbashi, S. (2010): Influence of hydraulic hysteresis on effective stress in unsaturated soils, Géotechnique, 60, 729-734.

7) Maeda, K. and Miura, K. (1999): Relative density dependency of mechanical properties of sands, Soils and Foundations, 39(1), 69-79.

8) Martin, C. M. (2004): User Guide for ABC-Analysis of Bearing Capacity, University of Oxford, U.K.

9) Mohamed, F. M. O. and Vanapalli, S. K. (2006): Laboratory investigations for the measurement of the bearing capacity of an unsaturated coarsegrainedsoil, Proceedings of 59th Canadian Geotechnical Conference, Canadian Geotechnical Society, Vancouver, BC, Canada, 219-226.

10) Nishimura, T., and Fredlund, D. G. (2002): Hysteresis effects resulting from drying and wetting under relatively dry conditions, Proceedings of 3rd International Conference on Unsaturated Soils, Swets and Zeitlinger, Lisse, 301-305.

11) Oh, W. T. andVanapalli, S. K. (2011): Modelling the applied vertical stress and settlement relationship of shallow foundations in saturated and unsaturated sands, Canadian Geotechnical Journal, 48, 425-438.

12) Oloo,S. Y. (1994): A bearing capacity approach to the design of low-volume traffic roads, Ph.D Thesis, University of Saskatchewan, Saskatoon, Canada.

13) Pedroso, D. M. (2015): A consistent u-p formulation for porous media with hysteresis, International Journal of Numerical Methods in Engineering, 101, 606-634.

14) Poulos, H. G. and Davis, E. H. (1974): Elastic solutions for soil and rock mechanics, John Wiley and Sons, New York.

15) Russell, A. R. (2010): Water retention characteristics of soils with double porosity, European Journal of Soil Science, 61, 412-424,

16) Russell, A. R. (2014): How water retention in fractal soils depends on particle and pore sizes, shapes, volumes and surface areas, Géotechnique, 64(5), 379-390.

17) Salgado, R., Bandini, P. andKarim, A. (2000): Shear strength and stiffness of silty sand, Journal of Geotechnical and Geoenvironmental Engineering, 126(5), 451-462.

18) Tang, Y., Taiebat, H. A. and Russell, A. R. (2017): Bearing capacity of shallow foundations in unsaturated soil considering hydraulic hysteresis and three drainage conditions, International Journal of Geomechanics, 10.1061/(ASCE)GM.1943-5622.0000845.

19) Vahefifard, F. and Robinson, J. D.(2016): Unified method for estimating the ultimate bearing capacity of shallow foundations in variably saturated soils under steady flow, Journal of Geotechnical and Geoenvironmental Engineering, 142(4), 04015095.

20) Vanapalli, S. K. and Mohamed, F. M. O. (2013): Bearing capacity and settlement of footings in unsaturated sands, International Journal of Geomate, 5(1), 595-604.

21) Vo, T., Taiebat, H. and Russell, A. R. (2016): Interaction of a rotating rigid retaining wall with an unsaturated soil in experiments, Géotechnique, 66(5), 366-377.

22) Xu, Y. (2004): Bearing capacity of unsaturated expansive soils.”Geotechnical and Geological Engineering, 22, 611-625.

23) Yang, H., Khoshghalb, A. and Russell, A. R. (2014): Fractal-based estimation of hydraulic conductivity from soil-water characteristic curves considering hysteresis, Géotechnique Letters, 4, 1-10.

24) Yang, H. and Russell, A. R. (2015): Cavity expansion in unsaturated soils exhibiting hydraulic hysteresis considering three drainage conditions, International Journal for Numerical and Analytical Methods in Geomechanics, 39, 1975-2016. 